\title{
Do Parents Talk about Emotions with Their Children? The Questionnaire of Parent-Child Conversations about Emotions (QPCCE)
}

\author{
Stéphanie Mazzone, Isabelle Roskam, Moïra Mikolajczak, Nathalie Nader-Grosbois \\ Psychological Sciences Research Institute, Chair Baron Frère in specialized education, Université catholique de Louvain, \\ Louvain-la-Neuve, Belgium \\ Email: nathalie.nader@uclouvain.be
}

How to cite this paper: Mazzone, S., Roskam, I., Mikolajczak, M., \& NaderGrosbois, N. (2017). Do Parents Talk about Emotions with Their Children? The Questionnaire of Parent-Child Conversations about Emotions (QPCCE). Psychology, 8, 987-1007.

https://doi.org/10.4236/psych.2017.87065

Received: April 6, 2017

Accepted: May 19, 2017

Published: May 22, 2017

Copyright $\odot 2017$ by authors and Scientific Research Publishing Inc. This work is licensed under the Creative Commons Attribution International License (CC BY 4.0).

http://creativecommons.org/licenses/by/4.0/

c) (i) Open Access

\begin{abstract}
Emotion-related conversations between parents and their children have been shown to play a crucial role in children's emotional development. During these conversations, parents may help their children to understand their own emotions and those of others better by emphasizing certain positive and negative emotions, by explaining causes and consequences of emotions, etc. In past research, parent-child emotion-related conversations have been assessed by means of an observational design. While this method has several advantages (e.g., ecological validity, qualitative data collection, etc.), it is time-consuming and generally restricted to one interaction. The goals of the present research were first to develop and validate a parent-report measure to evaluate parentchild emotion-related conversations (Questionnaire of Parent-Child Conversations about Emotions, QPCCE) (see Appendix) and then to examine its links with preschoolers' social and emotional development. Study 1 presents the factorial structure, the internal consistency and the test-retest reliability of the QPCCE. Study 2 presents its convergent validity with an observational measure. Study 3 examines the links between parental emotion-related conversations and children's social and emotional competences. The findings suggest that the QPCCE is a valid parent-report measure of parent-child emotion-related conversations, at least for mothers.
\end{abstract}

\section{Keywords}

Emotion-Related Conversations, Family Interaction, Children's Emotional Development, Validation, Parent-Report Measure

\section{Introduction}

Based on Parental Socialization of Emotions model (PSE model, Eisenberg, Spi- 
nrad, \& Cumberland, 1998), these studies aim to develop and validate an original parent-report measure assessing emotion-related conversations between parents and their children. While rare are studies using this methodological design, the originality of this measure is that it is a questionnaire assessing supportive and non-supportive strategies used by the parent during these conversations. By means of this tool, researchers and clinicians may have an easy way to obtain an indicator of parent-child emotion-related conversations for each parent.

\section{Literature Review}

There is an important individual variability in children's competences to express, understand or regulate their emotions, and these abilities play a crucial role in their social adaptation (Denham, 1986; Denham et al., 2003). Due to the importance of emotional competences, numerous authors have been interested in how they develop during childhood. In addition to genetic and intra-uterine factors, parents play a central role in their children's emotional development (Goldsmith \& Davidson, 2004). This parental influence occurs notably via their emotion-related socialization behaviors (ERSBs)-typical parental behaviors which affect children's understanding, expression and regulation of emotions (Eisenberg, Cumberland, \& Spinrad, 1998). In their PSE model, Eisenberg, Spinrad and Cumberland (1998: p. 320) distinguished three parental ERSBs: reactions to child's emotions, emotion-related conversations and emotional expressiveness. These authors suggest that parents may display supportive strategies such as helping to solve problems that upset children (problem-focused responses) or showing their acceptance of children's emotional displays by encouraging them to express emotions (encouragement). Conversely, parents may display non-supportive strategies such as denying the seriousness of emotional reactions or devaluing the problem (minimizing), or feeling embarrassed by their children's emotional display (discomfort). In the present research, we focused specifically on parental emotion-related conversations with preschoolers. Based on Vygotsky's theoretical background (1978), emphasizing the important role of language in children's development, researchers suggested that parentchild interactions, notably the discourse about emotions, could support preschoolers' emotional and social development by creating mental representations (e.g., Laible, 2004; Morelen \& Suveg, 2012; Ontai \& Thompson, 2008). During emotion-related conversations, mothers and fathers discuss about positive and negative emotions (e.g., Lagattuta \& Wellman, 2002; Ontai \& Thompson, 2002), emotional causes and consequences (e.g., Denham \& Auerbach, 1995; Lagattuta \& Wellman, 2002; Ruffman, Slade, \& Crowe, 2002), or the behavioral expression of emotions (Denham \& Auerbach, 1995; Ontai \& Thompson, 2002). Beyond this emotional content of the conversations, it's essential to target parents' strategies that are more efficient to foster the child's socio-emotional development. It was reported that the best predictors in emotion-related conversations of children's socio-emotional development, are the use of an elaborative style (e.g., Laible, 2004; Ontai \& Thompson, 2008), give explanations and a lot of detail about 
the emotional event and ask open-ended questions, or the use of supportive strategies (e.g. Morelen \& Suveg, 2012).

In most studies, parental emotion-related conversations are typically assessed by means of an observational design in which the parent and the child are invited to interact together and converse spontaneously (Jenkins, Turrell, Kogushi, Lollis, \& Ross, 2003; Lagattuta \& Wellman, 2002), or about a recent emotional event (Fivush, Brotman, Buckner, \& Goodman, 2000; Morelen \& Suveg, 2012; Ontai \& Thompson, 2002), or on the basis of pictures/books aimed at eliciting emotion-related conversations (e.g., Adrian, Clemente, Villanueva, \& Rieffe, 2005; Denham, Zoller, \& Couchoud, 1994; Garner, Dunsmore, \& Southam-Gerrow, 2008; LaBounty, Wellman, Olson, Lagattuta, \& Liu, 2008; Ontai \& Thompson, 2002). The vast majority of these studies have investigated mother-child emotion-related conversations (e.g., Adrian et al., 2005; Denham et al., 1994; Garner et al., 2008; Lagattuta \& Wellman, 2002; Ruffman, Slade, \& Crowe, 2002). Only a few of them have investigated father-child emotion-related conversations (Fivush et al., 2000; Jenkins et al., 2003; LaBounty et al., 2008; Morelen \& Suveg, 2012). Briefly, these studies have shown that mothers discuss about mental states more frequently than fathers, but parents do not differ in term of supportive and non-supportive strategies used during conversations.

In all studies, sessions were video-recorded and a coding grid or a computerized database was applied to analyze several categories of emotion-related conversations and mental states-related conversations. Table 1 summarizes the coding categories taken into account in these studies.

As indicated in the table, few studies analyzed emotion-related conversations in terms of supportive and non-supportive strategies displayed by parents. Yet it is important to have this information because the latest findings in the field show that parental supportive strategies are positively related with children's emotional development, while the opposite is true for non-supportive strategies. Therefore, with details about the parental profile of supportive and non-supportive strategies used during emotion-related conversations in the family, clinicians may be able to guide parents to improve their ERSBs in order to help children to understand and regulate their emotions better. Moreover, as the majority of researches (e.g., Eisenberg, Fabes, \& Murphy, 1996; Jones, Eisenberg, Fabes, \& MacKinnon, 2002; McElwain, Halberstadt, \& Volling, 2007) that study parental reactions to children's emotions have used the distinction between supportive and non-supportive reactions, the use of these two categories is more relevant, for searchers and clinicians, to compare with another parental ERSB.

While the use of an observational design to measure parent-child interactions has several advantages (e.g. ecological validity, qualitative data collection), it also bears some limitations. First, video recording may influence parents' and children's behavior (e.g., inhibit spontaneous behavior or induce a social desirability bias). Second, the coding after the observational step is time-consuming and necessitates two trained judges to ensure coding reliability. Third, because of the latter, the majority of studies have analyzed parental conversations with only one 
Table 1. Coding categories of relevant studies.

\begin{tabular}{|c|c|c|c|c|c|c|c|c|c|c|c|c|}
\hline & \multicolumn{7}{|c|}{ Targeted contents of emotion-related conversations } & \multicolumn{5}{|c|}{ Parental strategies } \\
\hline & \multicolumn{3}{|c|}{$\begin{array}{l}\text { Terms related to } \\
\text { mental states }\end{array}$} & \multirow[t]{2}{*}{$\begin{array}{l}\text { Emotional } \\
\text { causes }\end{array}$} & \multirow[t]{2}{*}{$\begin{array}{c}\text { Emotional } \\
\text { consequences }\end{array}$} & \multirow[t]{2}{*}{$\begin{array}{c}\text { Emotional } \\
\text { problem } \\
\text { solving }\end{array}$} & \multirow[t]{2}{*}{$\begin{array}{l}\text { Behavioral } \\
\text { expression } \\
\text { of emotion }\end{array}$} & \multirow[t]{2}{*}{$\begin{array}{c}\text { Emotion-related } \\
\text { questions }\end{array}$} & \multirow[t]{2}{*}{$\begin{array}{l}\text { Descriptions/ } \\
\text { explanations }\end{array}$} & \multirow[t]{2}{*}{$\begin{array}{l}\text { Elaborative } \\
\text { style }\end{array}$} & \multirow[t]{2}{*}{ SU } & \multirow[t]{2}{*}{ NSU } \\
\hline & $\begin{array}{l}\text { Emo. } \\
\text { state }\end{array}$ & $\begin{array}{l}\text { Cog. } \\
\text { state }\end{array}$ & $\begin{array}{l}\text { Des. } \\
\text { state }\end{array}$ & & & & & & & & & \\
\hline $\begin{array}{l}\text { Denham } \\
\text { et al., } 1994\end{array}$ & $\mathrm{X}$ & & & & & & $\mathrm{X}$ & & & & & \\
\hline Denham \& & & & & & & & & & & & & \\
\hline $\begin{array}{l}\text { Auerbach, } \\
1995\end{array}$ & $\mathrm{X}$ & & & $\mathrm{X}$ & $\mathrm{X}$ & & $\mathrm{X}$ & $\mathrm{X}$ & $\mathrm{X}$ & & & $\mathrm{X}$ \\
\hline $\begin{array}{l}\text { Fivush et al., } \\
\qquad 2000\end{array}$ & $\mathrm{X}$ & & & $\mathrm{X}$ & & & $\mathrm{X}$ & $\mathrm{X}$ & $\mathrm{X}$ & & & \\
\hline Lagattuta \& & & & & & & & & & & & & \\
\hline $\begin{array}{l}\text { Wellman, } \\
2002\end{array}$ & $\mathrm{X}$ & & & $\mathrm{X}$ & $\mathrm{X}$ & & & & & & & \\
\hline Ontai \& & & & & & & & & & & & & \\
\hline $\begin{array}{l}\text { Thompson, } \\
2002\end{array}$ & $\mathrm{X}$ & & & $\mathrm{X}$ & & $\mathrm{X}$ & $\mathrm{X}$ & $\mathrm{X}$ & $\mathrm{X}$ & & & \\
\hline $\begin{array}{l}\text { Ruffman } \\
\text { et al., } 2002\end{array}$ & $\mathrm{X}$ & $\mathrm{X}$ & $\mathrm{X}$ & $\mathrm{X}$ & & & & & $\mathrm{X}$ & & & \\
\hline $\begin{array}{l}\text { Jenkins } \\
\text { et al., } 2003\end{array}$ & $\mathrm{X}$ & $\mathrm{X}$ & $\mathrm{X}$ & & & & & & & & & \\
\hline Laible, 2004 & $\mathrm{X}$ & & & & & & & & & $\mathrm{X}$ & & \\
\hline $\begin{array}{c}\text { Reese, } \\
\text { Bird \& } \\
\text { Tripp, } 2007\end{array}$ & $\mathrm{X}$ & & & $\mathrm{X}$ & $\mathrm{X}$ & & & & $\mathrm{X}$ & & & \\
\hline $\begin{array}{l}\text { Garner } \\
\text { et al., } 2008\end{array}$ & $\mathrm{X}$ & & & $\mathrm{X}$ & $\mathrm{X}$ & & & & $\mathrm{X}$ & & & \\
\hline $\begin{array}{l}\text { LaBounty } \\
\text { et al., } 2008\end{array}$ & $\mathrm{X}$ & $\mathrm{X}$ & $\mathrm{X}$ & $\mathrm{X}$ & & & & & & & & \\
\hline Ontai \& & & & & & & & & & & & & \\
\hline $\begin{array}{l}\text { Thompson, } \\
2008\end{array}$ & $\mathrm{X}$ & & $\mathrm{X}$ & & & & & & & $\mathrm{X}$ & & \\
\hline Laible, 2011 & $\mathrm{X}$ & & & $\mathrm{X}$ & & & & & & $\mathrm{X}$ & & \\
\hline $\begin{array}{l}\text { Morelen \& } \\
\text { Suveg, } 2012\end{array}$ & & & & & & $\mathrm{X}$ & & $\mathrm{X}$ & & & $\mathrm{X}$ & $\mathrm{X}$ \\
\hline
\end{tabular}

Notes. Emo. $=$ emotional, Cog. $=$ cognitive, Des. $=$ desire, $\mathrm{SU}=$ supportive, $\mathrm{NSU}=$ non-supportive.

parent and during only one specific, brief moment, which may not be representative of the variability of parent-child interactions. Fourth, the variety of methodological designs (material, length of the session, etc.) and of coding categories through studies complicates the comparison of results between studies.

In order to overcome these limitations, we developed a parent-report measure to evaluate parent-child emotion-related conversations that could be useful for researchers and clinicians. For the reasons previously mentioned, this measure 
assessed supportive and non-supportive strategies displayed by parents during emotion-related conversations with their children. The goal of the studies presented hereafter was to develop and validate an original parent-report measure assessing emotion-related conversations between parents and their children. The development of the instrument was the focus of a preliminary research. The psychometric properties (factor structure, internal consistency, test-retest reliability, convergent validity and criterion validity) were explored in three further studies.

\section{Preliminary Research}

Based on knowledge accumulated in the field (see studies cited in Table 1), we created a questionnaire divided into two parts. The first part consisted of 44 items measuring several aspects of parental emotion-related conversations that were highlighted by previous studies: references to mental states (e.g., Over the past two weeks... When my child seemed sad, I asked him/her to explain what he/she was feeling), references to emotions' causes or consequences (e.g., Over the past two weeks... When my child talked to me about someone being afraid, I explained why that person was afraid), references to emotional problem-solving (e.g., Over the past two weeks... I talked with my child about different ways of managing his/her fear/sadness/anger), items relating to the behavioral expression of emotion (e.g., Over the past two weeks... When my child talked to me about another person's reaction, I explained that he/she had reacted like that because he/she was happy/angry/sad), emotion-related items (e.g., Over the past two weeks... When I was reading a story to my child or we were looking at a cartoon/comic, I asked him/her questions about the characters' feelings of fear/sadness/anger). Items were designed to reflect both supportive and nonsupportive strategies in reference to the PSE model (Eisenberg et al., 1998). Parents are asked to indicate on a 6-point scale (ranging from "never" to "always") how frequently the item applied in conversations with their children (if there were several preschool aged children in the family, parents were asked to respond to the questionnaire with reference to one of their children). The second part of the questionnaire consisted of a listing of emotional terms for the four basic emotions (joy, sadness, anger and fear) (Kotsou, 2009; LaBounty et al., 2008). Parents were asked to mark with a cross the terms that they usually used with their children during emotion-related conversations.

The two parts of this questionnaire, which we named the Questionnaire of Parent-Child Conversations about Emotions (QPCCE, see Appendix), was then submitted to 115 Belgian parents (92 mothers and 23 fathers) of children aged between 3 and 6.5 years. Based on item analyses and parents' opinions, some items were removed, revised or added. The final version of the questionnaire used in Study 1 included 37 items. We adjusted the instructions and the Likert scale. Using a 4 -point scale (" 0 time”-“ 1 or 2 times"-“ 3 or 4 times"-“ 5 times and more"), parents indicated the number of times they had experienced the situations described with their children during the past two weeks. We chose to ask 
parents to focus on the past two weeks in their responses in order to reduce the social desirability bias (i.e. the tendency to overrate items related to supportive strategies). We also provided a "not applicable" response option if the situation had not occurred during these two weeks.

\section{Study 1: Factor Structure, Internal Consistency and Test-Retest Reliability of the QPCCE}

\subsection{Method}

1) Participants

Parents from French-Speaking Belgian area with children between the ages of 3 and 6 years were recruited by emailing our professional network and parents' associations and by putting an information letter in the schoolbags of children at kindergarten. All participants were informed that data would be treated anonymously and used only for the study.

A first sample of 300 parents (168 mothers and 132 fathers) of preschool-aged children (150 girls and 150 boys, $M=4.53$; $\mathrm{SD}=0.95$ years) completed the QPCCE. The participants were predominantly Caucasian. The mothers' ages ranged from 24 to 51 years $(M=34.42$; $\mathrm{SD}=4.46)$ and they had primarily university (Master degree) (58\%) or graduate school (4-year undergraduate degree) (35\%) education level. The fathers' ages ranged from 29 to 69 years $(M=37.95$; $\mathrm{SD}=5.76)$ and most of them were educated to university $(47 \%)$ or graduate school (27\%) level. Most parents (95.3\%) spoke french as their first language. This first sample allowed us to examine the factorial structure and internal consistency of the QPCCE.

A subsample of 53 parents ( 46 mothers, $M=34.50$; $\mathrm{SD}=4.12$ and 7 fathers, $M=40.14$; SD $=12.78)$ of 27 girls and 26 boys aged from 3 years to 6.5 years $(M=$ 4.48; $\mathrm{SD}=0.99$ ) agreed to fill in the questionnaire a second time two weeks later (response rate $=53.54 \%$ ). This allowed us to assess test-retest reliability.

2) Measures.

Parent-child conversations about emotions. Emotion-related conversations were assessed using the QPCCE described in the introduction.

\subsection{Results}

1) Factorial structure and internal consistency.

As suggested by Field (2013), we checked the following conditions before exploring the factorial structure: sample size, correlations between variables and multicollinearity, normality of data. The result of the Kaiser-Meyer-Oklin measure of sampling adequacy $(\mathrm{KMO}=0.902)$ showed that our sample was large enough to perform a factorial analysis. The analysis of the other initial conditions allowed us to eliminate six problematic items. Five of these were items assessing non-supportive strategies.

The 31 items remaining were subjected to parallel analysis to determine the number of factors that best explained the structure by comparing between eigenvalues from a factor analysis of the actual data and eigenvalues (higher than 
the upper $95 \%$ confidence interval) from a factor analysis of a random dataset (Horn, 1965). Parallel analysis based on principal component analysis supported a two-factor structure when the 95th percentile was considered. The first two eigenvalues from the actual data were 10.91 and 1.83; the corresponding first two 95th percentile random data eigenvalues were 1.74 and 1.63 . The analysis of the results showed that one item (QPCCE_3) did not load on any factor, and six items (QPCCE_2; QPCCE_10; QPCCE_14; QPCCE_15; QPCCE_24; QPCCE_ 25) undermined the structure because of their conceptual framework (emotional coaching), which was different from that of the other items (PSE) (see Table 2

Table 2. Rotated factor loadings for two-factor solution.

\begin{tabular}{|c|c|c|}
\hline & NSUR & SUR \\
\hline QPCCE_1 & -0.045 & 0.465 \\
\hline QPCCE_2 & -0.022 & 0.625 \\
\hline QPCCE_3 & 0.259 & 0.118 \\
\hline QPCCE_4 & -0.032 & 0.649 \\
\hline QPCCE_5 & -0.076 & 0.760 \\
\hline QPCCE_6 & 0.015 & 0.558 \\
\hline QPCCE_7 & -0.055 & 0.738 \\
\hline QPCCE_8 & -0.029 & 0.595 \\
\hline QPCCE_9 & -0.022 & 0.732 \\
\hline QPCCE_10 & 0.194 & 0.578 \\
\hline QPCCE_11 & 0.102 & 0.709 \\
\hline QPCCE_12 & 0.072 & 0.534 \\
\hline QPCCE_13 & 0.144 & 0.507 \\
\hline QPCCE_14 & 0.379 & -0.233 \\
\hline QPCCE_15 & 0.511 & -0.269 \\
\hline QPCCE_16 & -0.162 & 0.487 \\
\hline QPCCE_17 & -0.147 & 0.445 \\
\hline QPCCE_18 & 0.048 & 0.419 \\
\hline QPCCE_19 & 0.049 & 0.653 \\
\hline QPCCE_20 & 0.009 & 0.629 \\
\hline QPCCE_21 & 0.657 & -0.116 \\
\hline QPCCE_22 & 0.763 & -0.080 \\
\hline QPCCE_23 & 0.179 & 0.446 \\
\hline QPCCE_24 & 0.422 & 0.332 \\
\hline QPCCE_25 & 0.513 & 0.238 \\
\hline QPCCE_26 & 0.620 & -0.305 \\
\hline QPCCE_27 & -0.201 & 0.636 \\
\hline QPCCE_28 & -0.204 & 0.658 \\
\hline QPCCE_29 & 0.618 & -0.249 \\
\hline QPCCE_30 & 0.042 & 0.715 \\
\hline QPCCE_31 & 0.154 & 0.537 \\
\hline
\end{tabular}

Notes. Factor loadings $>0.30$ are in bold, NSUR $=$ non-supportive, $\mathrm{SUR}=$ supportive. 
for loadings). After these items had been dropped, the final structure showed two factors: the first one grouping the supportive strategies (20 items) and the second one grouping the non-supportive strategies (4 items). Given the imbalance in terms of number of items between the two factors and results obtained after the parallel analysis (data eigenvalues and cross-loadings between the two factors), it seemed preferable to have a total score with reversed items for the non-supportive strategies (QPCCE_21; QPCCE_22; QPCCE_26; QPCCE_29). Reliability analysis, using Cronbach's alpha, indicated a very good consistency of the total score $(\alpha=0.91)$.

2) Test-retest stability.

The short-term stability of the QPCCE was assessed by the correlation between parents' scores obtained with a two-week interval. Pearson's correlation indicated a good stability $(r=0.60, p<0.00)$. The scores at Time 1 explained $35 \%$ of the variation in scores at Time 2 .

\subsection{Summary}

The goal of Study 1 was to explore the psychometric properties of the QPCCE. The results from factor analysis highlighted two factors that are theoretically consistent: supportive and non-supportive strategies. However, given the very few number of items for the second factor and results obtained after the parallel analysis, it was decided that a total score ("supportive strategies") should be calculated with reversed items for non-supportive strategies. The questionnaire showed very high internal consistency and moderate test-retest stability. These first findings suggested that the QPCCE is a reliable parent-report measure of parent-child emotion-related conversations. The convergent validity of the QPCCE was tested in Study 2 using an observational design assessing parental emotion-related conversations during a Picture-book Task. The criterion validity and clinical relevance of the QPCCE were investigated in Study 3 via the relations between parental emotion-related conversations and their children's social and emotional competences.

\section{Study 2: Convergent Validity of the QPCCE}

\subsection{Method}

1) Participants.

The participants recruited (Recruitment procedure is the same that in the Study 1) in French-Speaking Belgian area were 35 mothers (Mage $=35.26$; $\mathrm{SD}=$ $4.71)$ and 35 fathers (Mage $=37.31 ; \mathrm{SD}=5.52)$ and their children ( 23 girls and 12 boys) aged between 3 years and 1 month and 6 years and 8 months $(M=$ 57.51; $\mathrm{SD}=12.75$ months). The parents were educated to the following levels: secondary school (22.9\% of mothers, $37.1 \%$ of fathers), apprenticeship ( $0 \%$ of mothers, $5.7 \%$ of fathers), graduate school (4-year undergraduate degree) $(45.7 \%$ of mothers, $25.7 \%$ of fathers), university level (Master degree) (31.4\% of mothers, $31.4 \%$ of fathers). The participants were predominantly Caucasian. Regarding family constellation, all children lived with their two biological parents 
(100\%). During the week, the time spent with children vary for each parent: 1 - 2 hours per day (25.7\% of fathers and $5.9 \%$ of mothers), 3 hours per day $(22.9 \%$ of fathers and $14.7 \%$ of mothers), 4 hours per day (20.0\% of fathers and $32.4 \%$ of mothers), 5 hours per day (14.3\% of fathers and $20.6 \%$ of mothers), 6 hours per day $(8.6 \%$ of fathers and $8.8 \%$ of mothers), more than 6 hours per day $(8.6 \%$ of fathers and $17.6 \%$ of mothers). During the weekend, majority of fathers $(65.7 \%)$ and mothers $(88.6 \%)$ spend time with their child during more than six hours per day. All participants were free to participate and completed an informed consent form.

2) Measures.

Parent-child conversations about emotions. Emotion-related conversations were assessed using the QPCCE described in the introduction and with a Picture-book Task. The parent filled the QPCCE always after the Picture-book Task. An observational design was elaborated to measure conversations about emotions between parents and their children (Hanquet \& Rase, 2011). As in previous studies (LaBounty et al., 2008; Ruffman et al., 2002), we proposed a wordless Picture book Task ("Ça arrive à tout le monde", Bingham, 2007) to elicit conversations about emotions. We selected four books that each illustrated, in an explicit way, one of the four basic emotions (joy, sadness, anger and fear). We replicated each book to obtain two versions, one for the mother and one for the father. The pictures in the mother's version depicted a mother, while those in the father's version depicted a father. We obtained 8 short stories. For the joy scenarios, one story depict the preparation of a birthday party and the second one illustrate family sea vacations. For the sadness scenarios, one book is about a child who is scoffed by his/her friends and the second one depict the death of the family pet. For the anger scenarios, one book is about a child who is living a number of problems before arrive at school and the second one is about a child who is punished by the parent. For the fear scenarios, one book illustrate a child's first day of classes, and the second one depict a child who is lost in a supermarket. The parent was asked to do as usual when he/her reads a book with his/her child. The order of the dyad mother-child and father-child was counterbalanced. All sessions were video-recorded and a coding grid was applied to analyze parental supportive (e.g., ask questions about the emotion, explain emotional causes and consequences, comfort the child) and non-supportive strategies (e.g., minimizing, display embarrassment) used during emotion-related conversations for each emotion. The validation of the coding grid revealed moderate internal consistencies for supportive strategies ( $\alpha$ from 0.43 to 0.77 ), and good internal consistencies for non-supportive strategies ( $\alpha$ from 0.66 to 0.85 ). The inter-rater reliability for supportive strategies varied from $0.43(p<0.01)$ to $0.56(p<0.00)$ and for non-supportive strategies from $0.64(p<0.00)$ to $0.85(p<0.00)$.

\subsection{Results}

Convergent validity was analyzed by examining Pearson correlation between the total score of the QPCCE ("supportive strategies") and a composite score of 
"supportive strategies" (mean of supportive strategies of all emotions minus non-supportive strategies) assessed by the Picture-book Task. As expected, QPCCE_supportive strategies $(M=2.54$; SD $=0.46)$ and Picture-book Task_ supportive strategies $(M=8.64$; $\mathrm{SD}=2.80)$ were significantly correlated for mothers $(r=0.41, p=0.018)$. However, we did not obtain a significant correlation $(r=0.21, p=0.218)$ between QPCCE_supportive strategies $(M=2.35$; $\mathrm{SD}=$ $0.34)$ and Picture-book Task_supportive strategies $(M=7.79$; $\mathrm{SD}=2.95)$ for fathers. Moreover, the paired samples correlations revealed that maternal and paternal supportive strategies displayed during the Picture-book Task were significantly correlated $(r=0.510, p=0.002)$, while maternal and paternal strategies assessed by the QPCCE were not correlated ( $r=0.158, p=0.374)$.

\subsection{Summary}

The goal of Study 2 was to explore the convergent validity of the QPCCE with an observational design. The results confirmed the convergent validity for mothers but not for fathers. However, the significant correlation obtained between maternal and paternal supportive strategies displayed during the Picture-book Task could indicate a bias of the observational design by inhibiting fathers' spontaneous behaviors.

\section{Study 3: Criterion Validity of the QCPEE}

\subsection{Method}

1) Participants.

174 families from French-Speaking Belgian area were recruited via their children's schools. All participants were free to participate and completed an informed consent form. The analyses were based on the 125 of them for whom we had complete data for both mothers and fathers. Comparisons between the families included vs. excluded from the study revealed no differences between the two groups in demographic variables. The children (62 girls and 63 boys) were aged between 3 years and 3 months and 6 years and 1 month $(M=56.36$; SD = 9.05 months). On average, the mothers were 35 years old ( $\mathrm{SD}=4.36)$, and the fathers 38 years old $(S D=4.67)$. Both mothers and fathers had a very high level of education: 41.8 percent graduate school (4-year undergraduate degree) and 50 percent university (master degree) for mothers and 35.4 percent graduate school and 47.3 percent university for fathers. The participants were predominantly Caucasian. Concerning family constellation, the majority of children lived with their two biological parents $(94.1 \%)$. During the week, the time spent with children vary for each parent: $1-2$ hours per day $(20.6 \%$ of fathers and $7.1 \%$ of mothers), 3 hours per day (29.9\% of fathers and $25.5 \%$ of mothers), 4 hours per day $(30.9 \%$ of fathers and $31.6 \%$ of mothers), 5 hours per day $(10.3 \%$ of fathers and $21.4 \%$ of mothers), 6 hours per day (2.1\% of fathers and $9.2 \%$ of mothers), more than 6 hours per day $(6.2 \%$ of fathers and $5.1 \%$ of mothers). During the weekend, majority of fathers (85.6\%) and mothers (94.9\%) spend time with their child during more than six hours per day. 


\section{2) Measures.}

Parent-child conversations about emotions. Emotion-related conversations were assessed using the QPCCE described in the introduction. Cronbach's alpha in this study was 0.91 for emotion-related conversations for mothers and 0.83 for fathers.

Children's Theory of Mind abilities regarding emotions. These abilities were assessed via the ToM-emotions tasks developed by Nader-Grosbois and Thirion-Marissiaux (2011). These tasks assess children's recognition and understanding of causes and consequences of emotions. The first task ("The preliminary task of facial emotional expression recognition") aimed to ensure that children were able to recognize the four basic emotions (joy, sadness, anger and fear). The second task ("The causes of emotions task") assessed if children were able to understand the emotion felt by the protagonist of a story according to the situation with which he or she was confronted. Four stories, related to the four basic emotions, were told to the children. The response to each emotional script was scored between 0 and 1.5 points according to the participant's justification. The maximum score was 6 points in this task. The third task ("The consequences of emotions task") assessed if the child was able to predict the protagonist's behavior according to his or her emotion. As in the previous task, four stories, related to the four basic emotions, were told to the child. The response to each emotional script was scored between 0 and 1.5 point according to the participant's justification. The maximum score was 6 points in this task. A total score for ToM-emotions could be calculated.

The validation results were similar for the two tasks and revealed a very good inter-rater reliability $(r=0.96 ; p<0.01)$. Cohen's kappa averaged 0.92 and the test-retest stability (with an interval of 2 months) was excellent (0.99 and 0.98).

Children's Theory of Mind abilities. These abilities were assessed via the Theory of Mind Task Battery French version (ToM Task Battery, Hutchins, Prelock, \& Chace, 2008; French version, Nader-Grosbois \& Houssa, 2016). The ToM Task Battery consists of short situations presented in a story-book format. This measure was composed of 15 test questions in 9 tasks evaluating mental states separately (emotions, beliefs, desires, intentions, perspective-tak- ing, etc.), but also combined mental states (e.g., inference of protagonist's desire based on his emotions). Three scores could be obtained: a total score, a score for affective mental states and a score for cognitive mental states.

The validation of the French version revealed a Cronbach's alpha of 0.75 , a good coefficient of test-retest stability $(r=0.87 ; p<0.001)$ and a very good inter-rater reliability $(r=0.97 ; p<0.001)$.

Caregivers' perception of children's ToM abilities. The parent filled in the French version of the Theory of Mind Inventory (ToMI, Hutchins, Prelock, \& Bonazinga, 2012; French version, Houssa, Mazzone, \& Nader-Grosbois, 2014). This questionnaire was developed for children aged from 2 through 17 and consisted of 39 statements (for example, "My child understands that people can lie to purposely mislead others"). Caregivers indicated their degree of agreement 
with each statement concerning their children by placing the appropriate vertical mark along a continuum ranging from "definitely not" to "definitely". The score for each item ranged from 0 to 20 .

The validation of the French version matched that of the original version. The Cronbach's alpha was 0.94 , and the coefficient of test-retest stability was very significant $(r=0.86)$. Factor analysis revealed three factors for which Cronbach's alpha varied from 0.72 to 0.94 : the "ToMI-affective" factor (12 items), the "ToMI-beliefs" factor (8 items), the "ToMI-thinking" factor (19 items).

Caregivers' perception of children' emotionality and emotion regulation. The parent filled in the French version of the Emotion Regulation Checklist (ERC, Shields \& Cicchetti, 1997; French version, Nader-Grosbois \& Mazzone, 2015). This consisted of 24 items rated on a 4-point scale that indicated the frequency of emotion-related behaviors from 1 (never) to 4 (always). Two subscales composed this measure: Emotion Regulation (maximum score $=32$ ) and Lability/ Negativity (maximum score $=60$ ). The score on each subscale could be transformed into a mean score (maximum score $=4$ ).

The validation of the French version matched that of the original version. The Cronbach's alpha was 0.72 for the subscale "Emotion Regulation" and 0.82 for the subscale "Lability/Negativity".

Teachers' perception of children's social adjustment. Children's social adjustment was assessed using the Social Adjustment Scale (EASE, Hughes, SoaresBoucaud, Hochmann, \& Frith, 1997). This tool, inspired by conceptions of ToM in the social development, integrated items regarding children's abilities to take account of mental states in social relationships (ToM) and items about children's abilities to display social skills and respect for social rules (No-ToM). Parents indicated for each item if the behavior was usual for their children.

The validation results revealed a Cronbach's alpha of 0.79 for the No-ToM scale and 0.77 for the ToM scale.

\subsection{Results}

1) Descriptive statistics.

Means and standard deviation for children's social and emotional competences and for parental emotion-related conversations are summarized in Table 3. As can be seen from the table, children have better scores in ToM related to affective mental states than cognitive mental states. Moreover, they display high scores in emotional regulation and median scores in lability/negativity. Finally, they have better abilities to display social skills and respect for social rules than to take account of mental states in social relationships.

Parental emotion-related conversations and children's social and emotional competences.

As children's age may affect children's social and emotional competences (e.g., Holodynski \& Friedlmeier, 2006; Matthews, Goldberg, \& Lukowsky, 2013), we examined the correlation between these competences and parental emotion-related conversations after controlling for chronological age (see Table 4). 
Table 3. Descriptive statistics for Study 3 variables.

\begin{tabular}{ccc}
\hline & $M$ & SD \\
\hline Children's measures of social and emotional competences & & \\
ToM-emotions $(\max =12)$ & 9.01 & 3.32 \\
ToM task Battery-affective $(\max =6)$ & 5.01 & 1.08 \\
ToM task Battery-cognitive $(\max =6)$ & 2.29 & 1.52 \\
ToMI_affective $(\max =20)$ & 16.99 & 1.99 \\
ToMI_beliefs $(\max =20)$ & 17.08 & 1.96 \\
ToMI_thinking $(\max =20)$ & 12.75 & 2.61 \\
ERC_emotion regulation $(\max =4)$ & 3.31 & 0.33 \\
ERC_lability/negativity $(\max =4)$ & 2.00 & 0.35 \\
Social adjustment-No ToM $(\max =1)$ & 0.82 & 0.14 \\
Social adjustment-ToM $(\max =1)$ & 0.69 & 0.17 \\
$\quad$ Mother's' measures & & \\
Emotion-related conversations $(\max =4)$ & 2.57 & 0.39 \\
Fathers' measures & & \\
Emotion-related conversations $(\max =4)$ & 2.34 & 0.39 \\
\hline
\end{tabular}

Notes. $M=$ mean, $\mathrm{SD}=$ standard deviation, $\mathrm{ToM}=$ Theory of Mind, $\mathrm{ERC}=$ Emotion Regulation Checklist.

Table 4. Partial correlation between parental emotion-related conversations and children's social and emotional competences, controlling for children's chronological age.

\begin{tabular}{cccccc}
\hline & ToM-emotions & $\begin{array}{c}\text { ToM task } \\
\text { battery } \\
\text { Affective } \\
\text { score }\end{array}$ & $\begin{array}{c}\text { ToMI } \\
\text { Affective } \\
\text { score }\end{array}$ & $\begin{array}{c}\text { Emotional } \\
\text { regulation }\end{array}$ & $\begin{array}{c}\text { Social } \\
\text { adjustment }\end{array}$ \\
\hline Mothers & $0.350^{*}$ & $0.360^{* *}$ & $0.308^{*}$ & $0.316^{*}$ & ToM \\
Fathers & -0.017 & -0.209 & -0.092 & 0.083 & $0.330^{*}$ \\
\hline
\end{tabular}

Notes. ToM $=$ Theory of Mind, ${ }^{*} p<0.05,{ }^{* *} p<0.01$.

We observed that supportive strategies used by mothers during their emotion-related conversations were correlated with their children's ToM and emotion regulation abilities. By contrast, supportive strategies used by fathers were correlated with their children's social adjustment related to ToM abilities.

\section{General Discussion}

The goals of this research were to develop and validate an original parent-report measure assessing the emotion-related conversations between parents and their children, and to explore how these family conversations are related to children's social and emotional competences. Indeed, given that parental emotion-related conversations are typically assessed by means of an observational design, it had an interest for researchers and clinicians to develop a more easy use tool that may be used alone or complementarily with an observational task.

Study 1 provided initial evidence of reliability and validity for the QPCCE by exploring factorial structure, internal consistency and test-retest reliability. The 
results from factor analyses yielded a one-factor solution: 20 items assessing supportive strategies and 4 items assessing non-supportive strategies (reversed score). High scores indicates that parents converse spontaneously about emotions with their children, encourage them to explain their feelings, ask questions about emotions, explain the causes and consequences of emotions, take time to answer their children's questions about emotion, etc. The results indicate a good level of internal consistency and test-retest reliability.

Study 2 explored the convergent validity of the QPCCE with an observational design: a Picture-book Task that elicited parent-child emotion-related conversations. The results revealed that maternal supportive strategies assessed by our self-report measure were correlated with their supportive strategies displayed during an emotion discourse task (Cohen's $d=0.90$ ). In contrast, we did not obtain a significant relation for paternal supportive strategies (Cohen's $d=0.43$ ). The same discrepancy for fathers was obtained by Baker, Fenning and Crnic (2011) between a parent self-report of emotional coaching behaviors and an observation design eliciting these behaviors. This discrepancy may have two causes: either fathers naturally exhibit supportive strategies but are unaware of it, and therefore fail to report it in the questionnaire, or fathers do not spontaneously display such supportive strategies in daily life, but do so when they have a special moment with their children with materials that elicit conversations about emotions. It is also possible that the first explanation applies to some fathers and the second to others.

Study 3 investigated the clinical value of the QPCCE by examining the relation between parental emotion-related conversations and their children's social and emotional competences. Mothers' emotion-related conversations were positively related to children's emotion regulation. As described by Morelen and Suveg (2012), when their parents discussed emotion in a supportive way, children were better able to use adaptive emotion regulation behaviors. Moreover, similarly to the results of previous studies (LaBounty et al., 2008; Ruffman et al., 2002) our results showed that mothers' conversations were linked to children's ToM abilities, but only to affective mental states. This result highlighted that family emotion-related conversations may help children to understand their own and others' emotions better, but not necessarily other mental states related to ToM. Fathers' emotion-related conversations were positively related to children's abilities to take account of mental states in social relationships. Our results revealed that mothers' conversations seem to be more related to children's outcomes than fathers' conversations. This lack of result for fathers may be due to the fact that the QPCCE does not reflect what fathers do every day and therefore cannot predict children's outcomes. However, it could have other explanations. It may be due to the fact that fathers discuss emotions with their children less than mothers, and perhaps socialize children's emotional development by another way, namely their reactions to children's emotions (Mazzone \& Nader-Grosbois, 2016; McElwain et al., 2007). Another possibility, as suggested by Baker et al. (2011), is that fathers are more involved in the process of socializa- 
tion of emotion when children enter in middle childhood.

The foregoing results suggest that we have to be careful concerning the use of the QPCCE with fathers, and further studies should be conducted to gain a better understanding of fathers' involvement in the process of socialization. Moreover, other aspects of reliability and validity should be considered, such as testing convergent validity with another parental ERSB. As suggested by previous studies (Baker et al., 2011; Warren \& Stifter, 2008), it would also be interesting to explore the relations between parental emotion-related conversations and parental reactions toward their children's emotions: Are parents who react in a supportive way to their children's emotions those who frequently discuss emotions with their children? Moreover, our participants were predominantly Caucasian and most of them had a high level of education. Similar research needs to be conducted with more various families (other race, with a lower level of education and/or lower socioeconomic status, etc.) to assess whether the QPCCE is a widely applicable measure. In addition, it may also be important to examine the applicability of the QPCCE to parents of atypical children, such as children with an intellectual disability or an autistic spectrum disorder.

\section{Concluding Comment}

Our findings indicate that parents' emotion-related conversations with their children can be assessed by a parent-report measure, at least for mothers. The QPCCE appears to be a reliable and valid measure of this ERSB. Although further evidence of its psychometric properties and applicability needs to be gathered, we believe the QPCCE will be an interesting tool for researchers and clinicians. We think the development of the QPCCE responds to a lack in the field. It allows researchers to conduct studies exploring the three ERSBs identified by Eisenberg et al. (1998) with the same form of assessment: a parent-report measure. Given the ease of use of a questionnaire compared with an observational design, researchers can also conduct longitudinal studies to examine predictive or bidirectional links between parental strategies and children's emotional competences. For clinicians, this tool is any easy way to obtain an indicator of parental emotion-related conversations for each parent in order to help them identify and improve their own ERSBs.

\section{Ethical Approval}

All procedures performed in this study involving human participants were in accordance with the ethical standards of the institutional research committee and with the 1964 Helsinki declaration and its later amendments or comparable ethical standards.

\section{References}

Adrian, J. E., Clemente, R. A., Villanueva, L., \& Rieffe, C. (2005). Parent-Child PictureBook Reading, Mothers' Mental State Language and Children's Theory of Mind. Journal of Child Language, 32, 673-686. https://doi.org/10.1017/S0305000905006963 
Baker, J. K., Fenning, R. M., \& Crnic, K. A. (2011). Emotion Socialization by Mothers and Fathers: Coherence among Behaviors and Associations with Parent Attitudes and Children's Social Competence. Social Development (Oxford, England), 20, 412-430.

Bingham, J. (2007). Ça arrive à tout le monde. Paris : Les deux souris.

Denham, S. A. (1986). Social Cognition, Prosocial Behavior, and Emotion in Preschoolers: Contextual Validation. Child Development, 57, 194-201. https://doi.org/10.2307/1130651

Denham, S. A., \&Auerbach, S. (1995). Mother-Child Dialogue about Emotions and Preschoolers' Emotional Competence. Genetic, Social, and General Psychology Monographs, 121, 313-337.

Denham, S. A., Blair, K. A., DeMulder, E., Levitas, J., Sawyer, K., Auerbach-Major, S., \& Queenan, P. (2003). Preschool Emotional Competence: Pathway to Social Competence? Child Development, 74, 238-256. https://doi.org/10.1111/1467-8624.00533

Denham, S. A., Zoller, D., \& Couchoud, E. A. (1994). Socialization of Preschoolers' Emotion Understanding. Developmental Psychology, 30, 928-936.

https://doi.org/10.1037/0012-1649.30.6.928

Eisenberg, N., Cumberland, A., \& Spinrad, T. L. (1998). Parental Socialization of Emotion. Psychological Inquiry, 9, 241-273. https://doi.org/10.1207/s15327965pli0904_1

Eisenberg, N., Fabes, R. A., \& Murphy, B. C. (1996). Parents' Reactions to Children's Negative Emotions: Relations to Children's Social Competence and Comforting Behavior. Child Development, 67, 2227-2247. https://doi.org/10.2307/1131620

Eisenberg, N., Spinrad, T. L., \& Cumberland, A. (1998). The Socialization of Emotion: Reply to Commentaries. Psychological Inquiry, 9, 317. https://doi.org/10.1207/s15327965pli0904_17

Field, A. (2013). Discovering Statistics Using IBM SPSS Statistics. Los Angeles, CA: SAGE.

Fivush, R., Brotman, M., Buckner, J., \& Goodman, S. (2000). Gender Differences in Parent-Child Emotion Narratives. Sex Roles, 42, 233-253.

https://doi.org/10.1023/A:1007091207068

Garner, P. W., Dunsmore, J. C., \& Southam-Gerrow, M. (2008). Mother-Child Conversations about Emotions: Linkages to Child Aggression and Prosocial Behavior. Social Development, 17, 259-277. https://doi.org/10.1111/j.1467-9507.2007.00424.x

Goldsmith, H. H., \& Davidson, R. J. (2004). Disambiguating the Components of Emotion Regulation. Child Development, 75, 361-365. https://doi.org/10.1111/j.1467-8624.2004.00678.x

Hanquet, A., \& Rase, C. (2011). Stratégies parentales de socialisation des émotions et impact sur les compétences en Théorie de l'Esprit chez des enfants tout-venant et présentant une déficience intellectuelle d'âge de développement de niveau préscolaire. Unpublished Master's Thesis, Louvain-la-Neuve: Université catholique de Louvain.

Holodynski, M., \& Friedlmeier, W. (2006). Development of Emotions and Their Regulation. New York, NY: Springer.

Horn, J. L. (1965). A Rationale and Test for the Number of Factors in Factor Analysis. Psychometrika, 30, 179-185. https://doi.org/10.1007/BF02289447

Houssa, M., Mazzone, S., \& Nader-Grosbois, N. (2014). Validation d'une version francophone de l'inventaire de la Théorie de l'Esprit (ToMI-vf). Revue Européenne de Psychologie Appliquée/European Review of Applied Psychology, 64, 169-179.

Hughes, C., Soares-Boucaud, I., Hochmann, J., \& Frith, U. (1997). Social Behaviour in Pervasive Developmental Disorders: Effects of Informant, Group and "Theory-of- 
Mind”. European Child \& Adolescent Psychiatry, 6, 191-198.

https://doi.org/10.1007/s007870050029

Hutchins, T. L., Prelock, P. A., \& Chace, W. (2008). Test-Retest Reliability of a Theory of Mind Task Battery for Children with Autism Spectrum Disorders. Focus on Autism \& Other Developmental Disabilities, 23, 195-206.

https://doi.org/10.1177/1088357608322998

Hutchins, T. L., Prelock, P. A., \&Bonazinga, L. (2012). Psychometric Evaluation of the Theory of Mind Inventory (ToMI): A Study of Typically Developing Children and Children with Autism Spectrum Disorder. Journal of Autism Developmental Disorder, 42, 327-341. https://doi.org/10.1007/s10803-011-1244-7

Jenkins, J. M., Turrell, S. L., Kogushi, Y., Lollis, S., \& Ross, H. S. (2003). A Longitudinal Investigation of the Dynamics of Mental State Talk in Families. Child Development, 74, 905-920. https://doi.org/10.1111/1467-8624.00575

Jones, S., Eisenberg, N., Fabes, R. A., \& MacKinnon (2002). Parents' Reactions to Elementary School Children's Negative Emotions: Relations to Social and Emotional Functioning at School. Merrill-Palmer Quarterly, 48, 133-159.

https://doi.org/10.1353/mpq.2002.0007

Kotsou, I. (2009). L'expression et l'écoute des émotions. In M. Mikolajczak, J. Quoidbach, I. Kotsou, \& D. Nélis (Eds.), Les compétences émotionnelles (pp. 89-104). Paris: Dunod.

LaBounty, J., Wellman, H. M., Olson, S., Lagattuta, K., \& Liu, D. (2008). Mothers' and Fathers' Use of Internal State Talk with their Young Children. Social Development, 17, 757-775. https://doi.org/10.1111/j.1467-9507.2007.00450.x

Lagattuta, K. H., \& Wellman, H. M. (2002). Differences in Early Parent-Child Con- versations about Negative versus Positive Emotions: Implications for the Development of Psychological Understanding. Developmental Psychology, 38, 564-580. https://doi.org/10.1037/0012-1649.38.4.564

Laible, D. (2004). Mother-Child Discourse in Two Contexts: Links with Child Temperament, Attachment Security, and Socioemotional Competence. Developmental Psychology, 40, 979-992. https://doi.org/10.1037/0012-1649.40.6.979

Laible, D. (2011). Does It Matter If Preschool Children and Mothers Discuss Positive vs. Negative Events During Reminiscing? Links with Mother-reported Attachment, Family Emotional Climate, and Socioemotional Development. Social Development, 20, 394 411.

Matthews, N. L., Goldberg, W. A., \& Lukowski, A. F. (2013). Theory of Mind in Children with Autism Spectrum Disorder: Do Siblings Matter? Autism Research, 6, 443-453. https://doi.org/10.1002/aur.1308

Mazzone, S., \& Nader-Grosbois, N. (2016). How Are Parental Reactions to Children's Emotions Related to Their Theory of Mind Abilities? Psychology, 7, 166-179. https://doi.org/10.4236/psych.2016.72019

McElwain, N. L., Halberstadt, A. G., \& Volling, B. L. (2007). Mother- and Father- Reported Reactions to Children's Negative Emotions: Relations to Young Children's Emotional Understanding and Friendship Quality. Child Development, 78, 1407-1425. https://doi.org/10.1111/j.1467-8624.2007.01074.x

Morelen, D., \& Suveg, C. (2012). A Real-Time Analysis of Parent-Child Emotion Discussions: The Interaction Is Reciprocal. Journal of Family Psychology, 26, 998- 1003. https://doi.org/10.1037/a0030148

Nader-Grosbois, N., \& Houssa, M. (2016). La Batterie de tâches de Théorie de l'esprit: Validation de la version francophone. Enfance, 2016, 141-166. 
https://doi.org/10.4074/S0013754516002019

Nader-Grosbois, N., \& Mazzone, S. (2015). Validation de la version francophone de l'Emotion Regulation Checklist (ERC-vf). Revue Européenne de Psychologie Appliquée/European Review of Applied Psychology, 65, 29-41.

Nader-Grosbois, N., \& Thirion-Marissiaux, A.-F. (2011). Evaluer la compréhension des états mentaux émotions et croyances. In N. Nader-Grosbois (Ed.), La théorie de l'esprit: Entre cognition, émotion et adaptation sociale (pp. 95-125). Bruxelles: De Boeck. https://doi.org/10.3917/dbu.nader.2011.01.0093

Ontai, L. L. \& Thompson, R. A. (2008). Attachment, Parent-Child Discourse and Theory-of-Mind Development. Social Development, 17, 47-60. https://doi.org/10.1111/j.1467-9507.2007.00414.x

Ontai, L. L., \& Thompson, R. A. (2002). Patterns of Attachment and Maternal Discourse Effects on Children's Emotion Understanding from 3 to 5 Years of Age. Social Development, 11, 433-450. https://doi.org/10.1111/1467-9507.00209

Reese, E., Bird, A., \& Tripp, G. (2007). Children's Self-Esteem and Moral Self: Links to Parent-Child Conversations Regarding Emotion. Social Development, 16, 460-478.

Ruffman, T., Slade, L., \& Crowe, E. (2002). The Relation between Children's and Mothers' Mental State Language and Theory-of-Mind Understanding. Child Development, 73, 734-751. https://doi.org/10.1111/1467-8624.00435

Shields, A., \& Cicchetti, D. (1997). Emotion Regulation among School-Age Children: The Development and Validation of a New Criterion Q-Sort Scale. Developmental Psychology, 33, 906-916. https://doi.org/10.1037/0012-1649.33.6.906

Vygotsky, L. (1978). Mind in Society. Cambridge, MA: Harvard University Press.

Warren, H. K., \& Stifter, C. A. (2008). Maternal Emotion-Related Socialization and Preschoolers' Developing Emotion Self-awareness. Social Development, 17, 239- 258.

https://doi.org/10.1111/j.1467-9507.2007.00423.x 


\section{Appendix}

The Questionnaire of Parent-Child Conversations about Emotions (QPCCE, Mazzone, Roskam, Mikolajczak \& Nader-Grosbois, 2017).

\section{Dear Parents,}

We would like to ask you some questions about expressing feelings and talking about feelings with your child in your daily life.

We wish to ask you to think about the last two weeks. For each of the statements below, please indicate how many times you have experienced this kind of situation with your child during this period. You can choose between the following answers:
$0 \mathrm{X}$
$1-2 \mathrm{X}$
3-4X
$5 \mathrm{X}$ or more
not applicable

Tick the box of your choice after each statement.

You can only tick one box per statement.

If the situation has not occurred during the last two weeks, please tick "not applicable”.

If the situation has occurred, but you have not had the opportunity to act in the way described, please tick " $0 \mathrm{X}$ ".

Indicate the frequency of your actual interaction with your child. There is no right or wrong answer.

\begin{tabular}{|c|c|c|c|c|c|c|}
\hline & During the last two weeks... & $0 \mathrm{X}$ & $1-2 \mathrm{X}$ & $3-4 \mathrm{X}$ & $\begin{array}{l}5 \mathrm{X} \text { or } \\
\text { more }\end{array}$ & $\begin{array}{c}\text { not } \\
\text { applicable }\end{array}$ \\
\hline 1 & $\begin{array}{l}\text { When my child came home happy after being out (at school, with friends } \\
\text { or family, etc.), we talked together about his/her feelings }\end{array}$ & $\square$ & $\square$ & $\square$ & $\square$ & $\square$ \\
\hline 2 & $\begin{array}{l}\text { When my child came home angry after being out (at school, with friends } \\
\text { or family, etc.), we talked together about his/her feelings }\end{array}$ & $\square$ & $\square$ & $\square$ & $\square$ & $\square$ \\
\hline 3 & $\begin{array}{l}\text { When my child seemed afraid of something, I asked him/her to explain } \\
\text { what he/she was feeling }\end{array}$ & $\square$ & $\square$ & $\square$ & $\square$ & $\square$ \\
\hline 4 & $\begin{array}{l}\text { When my child seemed angry, I asked him/her to explain what he/she } \\
\text { was feeling }\end{array}$ & $\square$ & $\square$ & $\square$ & $\square$ & $\square$ \\
\hline 5 & $\begin{array}{l}\text { After my child had been afraid of something (e.g., a dog) during an } \\
\text { activity (e.g., on a walk), we talked together about what had happened }\end{array}$ & $\square$ & $\square$ & $\square$ & $\square$ & $\square$ \\
\hline 6 & $\begin{array}{l}\text { When my child seemed pleased, I asked him/her to explain what he/she } \\
\text { was feeling }\end{array}$ & $\square$ & $\square$ & $\square$ & $\square$ & $\square$ \\
\hline 7 & $\begin{array}{l}\text { When my child talked to me about someone being sad, I explained why } \\
\text { that person was sad } \\
\text { Example. Your friend is sad because he has lost his teddy. }\end{array}$ & $\square$ & $\square$ & $\square$ & $\square$ & $\square$ \\
\hline 8 & $\begin{array}{l}\text { When my child talked to me about someone being happy, I explained why } \\
\text { that person was happy } \\
\text { Example: Tom is happy because his dad picked him up from school }\end{array}$ & $\square$ & $\square$ & $\square$ & $\square$ & $\square$ \\
\hline 9 & $\begin{array}{l}\text { When my child talked to me about his/her brother/sister/friend being } \\
\text { angry, I explained to him/her why that person was angry } \\
\text { Example. Your brother is angry because he can't go to his friend s } \\
\text { birthday party }\end{array}$ & $\square$ & $\square$ & $\square$ & $\square$ & $\square$ \\
\hline 10 & $\begin{array}{l}\text { When my child talked to me about another person's reaction, I explained } \\
\text { that he/she had reacted like that because he/she was happy/angry/sad }\end{array}$ & $\square$ & $\square$ & $\square$ & $\square$ & $\square$ \\
\hline
\end{tabular}




\section{Continued}

When I was reading a story to my child or we were looking at a

11 cartoon/comic, I asked him/her questions about the characters' feelings of fear/sadness/anger

Example. Oh look, Tchoupi has lost his teddy bear. How does he feel?

When I was reading a story to my child or we were looking at a cartoon/comic, I asked him/her questions about the characters' feelings of happiness

Example: Oh look, Tchoupi has been given a present. How does he fee?

13 I encouraged my child to talk about his/her feelings

When my child talked to me about someone being afraid, I explained why that person was afraid

Example. Your sister was afraid because she saw a spider.

I talked with my child about different ways of managing his/her fear/sadness/anger

Example. When you are afraid in bed at night, you can turn on the light to be less afraid.

When I talked to my child about positive feelings (happiness, surprise) and we disagreed, I argued in order to bring him/her round to my viewpoint

When I talked to my child about negative feelings (sadness, fear, anger)

17 and we disagreed, I argued in order to bring him/her round to my viewpoint

When my child seemed sad, I asked him/her to explain what he/she was feeling

When my child was angry, I encouraged him/her to calm down so as not to show his/her feelings

When I was reading a story to my child or we were looking at a cartoon/comic, I answered his/her questions about the characters' feelings of fear/sadness/anger Example. Simba is sad because his father is dead.

When I was reading a story to my child or we were looking at a cartoon/comic, I answered his/her questions about the characters' feelings of happiness

Example. Simba is happy because he is with his father

When my child experienced positive feelings, it wasn't necessary to talk to him/her about them

When my child asked me questions about someone being 


\begin{tabular}{|c|c|c|c|}
\hline$\square$ Nice & $\square$ Cross & $\square \mathrm{Sad}$ & $\square$ Anxious \\
\hline$\square$ Amused & $\square$ Upset & $\square$ Despondent & $\square$ Panicking \\
\hline$\square$ Confident & $\square$ Angry & $\square$ Shattered & $\square$ Appalled \\
\hline$\square$ Contented & $\square$ Put out & $\square$ Despairing & $\square$ Sick with worry \\
\hline$\square$ In a good mood & $\square$ Furious & $\square$ Saddened & $\square$ Shocked \\
\hline$\square$ Excited & $\square$ Frustrated & $\square$ Distressed & $\square$ Uneasy \\
\hline$\square$ Glad & $\square$ Exasperated & $\square$ Depressed & $\square$ Horrified \\
\hline$\square$ Surprised & $\square$ Displeased & $\square$ Worried & $\square$ Frightened \\
\hline$\square$ Cheerful & $\square$ Enraged & $\square$ Bothered & $\square$ Terror-stricken \\
\hline$\square$ Delighted & $\square$ Irritated & $\square$ Troubled & $\square$ Trembling \\
\hline$\square$ Keen & $\square$ Wound up & $\square$ Distraught & $\square$ Concerned \\
\hline$\square$ Jolly & $\square$ On edge & $\square$ Unhappy & $\square$ Terrified \\
\hline$\square$ Overjoyed & $\square$ In a bad mood & $\square$ Affected & $\square$ Fearful \\
\hline$\square$ Cheery & & & $\square$ Perceive \\
\hline$\square$ Happy & & & $\square$ Appreciate \\
\hline$\square$ Joyful & & & $\square \mathrm{Be}$ \\
\hline$\square$ Thrilled & & & $\square$ Sense \\
\hline$\square$ Satisfied & & & $\square$ Feel \\
\hline & & & $\square$ Experience \\
\hline
\end{tabular}

Submit or recommend next manuscript to SCIRP and we will provide best service for you:

Accepting pre-submission inquiries through Email, Facebook, LinkedIn, Twitter, etc. A wide selection of journals (inclusive of 9 subjects, more than 200 journals) Providing 24-hour high-quality service User-friendly online submission system Fair and swift peer-review system Efficient typesetting and proofreading procedure Display of the result of downloads and visits, as well as the number of cited articles Maximum dissemination of your research work

Submit your manuscript at: http://papersubmission.scirp.org/

Or contact psych@scirp.org 